1352-2310(94)00329-7

\title{
DETECTION OF PEROXYACETYL NITRATE AT PHYTOTOXIC LEVEL AND ITS EFFECTS ON VEGETATION IN TAIWAN
}

\author{
EN-JANG SUN and MING-HUEI HUANG \\ Department of Plant Pathology and Entomology, National Taiwan University, Taipei, Taiwan, \\ R. O. China
}

(First received 17 November 1993 and in final form 20 September 1994)

\begin{abstract}
Symptoms of toxicity of peroxyacetyl nitrate (PAN), namely bronzing and silvering, were initially discovered on lettuce plants in the Taipei area in 1989. The cause and effect relationship was cstablished by the detcetion of large ambient concentrations of PAN and by reproduction of the symptoms upon exposure to PAN. In the following years, several other plants including spinach, Solanum nigrum, Nicotiana excelsior, and Galinsoga parviflora were also found with symptoms of a similar nature. Symptoms were artificially reproduced in these plants on exposure to PAN proving that they were also sensitive to PAN. These PAN-type symptoms were prominently different from those caused by ozone or other general pollutants described in the literature. Based on these symptoms, PAN is believed to occur in all three major urban areas of Taiwan, namely Taipei in the north, Taichung in the center, and Kaohsiung in the south. Hydrocarbons emitted from numerous motorcycles are believed to be the principal precursor of this photochemical pollutant. Ambient measurements of PAN in the Taipei area showed that on calm sunny days, PAN typically exceeded 4-12 ppb, and native Sword-leaf lettuce began to show the symptoms the next morning. From July 1992 to April 1993 there were at least $34 \mathrm{~d}$ with PAN at significantly phytotoxic concentrations that affected lettuce and other plants. The concentration of PAN was highly correlated with that of ozone according to the regression equation $Y$ (ozone/ppbv) $=16.9 X(\mathrm{PAN} / \mathrm{ppbv})+13.5$ in warm seasons, and $Y$ (ozone $/ \mathrm{ppbv})=3.0 X(\mathrm{PAN} / \mathrm{ppbv})+11.1$ in cooler seasons, indicating the co-occurrence but distinct ratios of these pollutants.
\end{abstract}

Key word index: Peroxyacetyl nitrate, ozone, Taiwan, vegetation injury.

\section{INTRODUCTION}

Peroxyacetyl nitrate (PAN) is a major phytotoxic component of photochemical smog that was first found in southern California after 1950 (Middleton $e t$ al., 1950; Jacobson and Hill, 1970). The characteristic symptoms caused by PAN were found even much earlier in 1944 by Middleton et al. (1950). Only in 1960 was PAN identified and the analysis of this gas available (Stephen et al., 1961; Darley et al., 1963; Stephen, 1969). In addition to PAN, other peroxyacyl nitrates (PANs) also exist in a polluted atmosphere. They are peroxypropionyl nitrate (PPN), peroxybutyryl nitrate $(\mathrm{PBN})$ and peroxybenzoyl nitrate $(\mathrm{PBzN})$. PAN is also implicated in the long-range transport of $\mathrm{NO}_{2}$ (Brice et al., 1984) and is believed to represent an important reservoir for atmospheric nitrogen oxides (Singh and Hanst, 1981).

The threshold phytotoxic dose of PAN defined by Temple and Taylor (1983) was $15 \mathrm{ppb}$ for $4 \mathrm{~h}$ during the forenoon period or $25 \mathrm{ppb}$ for $4 \mathrm{~h}$ in the afternoon period, although the threshold level is affected significantly by light conditions (Taylor et al., 1961). The potentially phytotoxic episodes occurred 27 times in Riverside in 1980 (Temple and Taylor, 1983). By contrast, PAN normally averaged $1 \mathrm{ppb}$ or less outside southern California, leading to the conclusion that PAN by itself did not appear to be a major cause of photochemical oxidant injury to vegetation in most regions (Temple and Taylor, 1983).

Injury symptoms to vegetation due to PAN, however, were first noticed in 1989 on the local Sword-leaf and Round-leaf cultivars of lettuce (Lactuca sativa $\mathrm{L}$.) at Taipei, Taiwan (Sun, 1992, 1993). Both cultivars showed characteristic symptoms of bronzing and silvering on the lower surfaces especially on the fully developed young leaves in the field. Exposure tests with synthesized PAN in continuously stirred tank reactors (CSTR) confirmed that these symptoms belonged to PAN but not ozone that might occur also (Sun, 1993). The two native cultivars of lettuce were found to be resistant to ozone but sensitive to PAN; these could therefore be used as ideal floral indicators of PAN in the Taiwan area (Sun, 1993). The exposure experiment also showed that when an episode of phytotoxic PAN occurred, only about 3-5 young 
leaves from the top on each plant were affected. The old and very young leaves were resistant. The symptoms appeared typically one or two days after exposure and were distributed in transverse bands that were located at the apex of very young leaves, the upper portion of young leaves, and the lower portion of mature leaves (Sun, 1993). These two cultivars are cultivated all year round and are rapid in growth, producing a new alternate leaf approximately every $3 \mathrm{~d}$. Therefore, continual development of leaves of Sword-leaf lettuce in a certain area can furnish an historical record of PAN exposures. Subsequent surveys showed that PAN injury to these vegetables occurred also in the Taichung and Kaohsiung areas (Sun, 1993). Estimation of the total area affected ranged from 1000 to 10,000 ha (Sun, 1992). Occasionally the injury caused yield loss greater than $60 \%$.

In addition to native lettuce, similar symptoms were found on spinach, black nightshade (Solanum nigrum L.), Galinsoga parviflora Canv., Nicotiana excelsior, petunia, Swiss chard (Beta vulgaris L. var. cicla), and Ocimum basilicum L. in recent years. Most species developed silvering or bronzing symptoms on the lower leaf surface, distributed in transverse bands on young leaves. The symptoms were similar to those described in the literature (Jacobson and Hill, 1970), but the relationship of cause and effect has not yet been established.

PAN is generally measured with a gas chromatograph having an electron capture detector (GC-ECD) (Darley et al., 1963; Stephen et al., 1969; Buhr, 1990). After the establishment of a PAN measuring system that included GC-ECD in 1991, PAN concentrations in Taipei area were first successfully determined in February 1992 (Sun, 1993). During days of severe pollution PPN was also detected (Sun, 1993). The first one-month monitoring data in June 1992 showed that PAN was detectable in the day time of $16 \mathrm{~d}$, during which PAN exceeded the phytotoxic level on $3 \mathrm{~d}$ based on the indicator plant lettuce showing the symptoms the following morning (Sun, 1993). The monitoring data showed also that PAN was undetectable on rainy, cloudy or windy days, and was detectable only on calm sunny days (Sun, 1993).

Why Taiwan has this PAN problem is an interesting topic for an environmentalist. In this report, we describe the results from continuing studies on the PAN problem in Taiwan and its effects on vegetation.

\section{MATERIALS AND METHODS}

\subsection{Measurement of PAN in Taipei area}

A gas chromatograph (Varian 3400) with a Ni-63 electron capture detector which has been described previously (Sun, 1993) was set up at National Taiwan University in Taipei to monitor the ambient PAN concentrations in that area. Each time an air sample of $2 \mathrm{ml}$ was manually introduced into the instrument using a gas-tight syringe. The carriage gas was ultra-pure nitrogen at a flow rate of $40 \mathrm{ml} \mathrm{min}-1$. A Teflon column (o.d. $3.2 \mathrm{~mm}$, length $100 \mathrm{~cm}$ ) packed with Carbowax $400(5 \%)$ on Chromosorb G-AW (100-120 mesh) (Katz, 1977) maintained at $30 \pm 1{ }^{\circ} \mathrm{C}$ was used for gas separation. The detector temperature was also $30 \pm 1^{\circ} \mathrm{C}$. Retention time for PAN was about $1.8 \mathrm{~min}$ and for PPN about $2.3 \mathrm{~min}$. The column and detector were cleaned thermally by elevation of the temperature to 80 and $150^{\circ} \mathrm{C}$, respectively, overnight whenever needed. There are no known interferences with this method (Katz, 1977). The sensitivity limit is less than $0.1 \mathrm{ppbv}$. The precision and accuracy were reported to be 2 and $5 \%$, respectively (Katz, 1977).

A nitrogen oxide analyzer (Model 42 of Thermo Environmental Instrument Co.) was used as calibrator for PAN measurements following a procedure similar to that described by Joos and Landolt (1986). Pure PAN was synthesized by the method reported by Gaffney et al. (1984) with tridecane as a heavy lipid solvent except that the period of nitrification reaction was lengthened to $20 \mathrm{~min}$ and the final step of separation with water was omitted. In order to produce the gaseous PAN of constant concentration for calibration and for exposure test described below, PAN in tridecane was constantly dispensed onto a volatizing disc (a $9 \mathrm{~cm}$ plastic petri dish with a $9 \mathrm{~cm}$ filter paper of Whatman 1PS) from a dispensing bottle with constant liquid surface level kept by a feeding bottle. The whole system is similar to the HF fumigator as designed by Sun and Su (1985), except that an ice bath is applied to the feeding and dispensing bottles for keeping the temperature lower than $10^{\circ} \mathrm{C}$ and the volatizing disc is modified to be fixed in the center of a gastight chamber (a $2 \ell$ plastic beaker with a rubber-bound membrane cover) which has only two openings on its wall, one is connected to a compression pump for bringing the clean air in, another is to the plexiglas chamber for calibration or to the CSTR for exposure tests. Since the evaporation rate of PAN from its solution is constant when the physical conditions are constant, the concentrations in the chamber or CSTR can also be kept constant. The preliminary monitoring of PAN in the chamber or CSTR has proved the stability and validity of this design.

A co-located ozone monitor (Model 49 of Thermo Environmental Instrument $\mathrm{Co}$.) was also operated concurrently. The linear regression relationships between PAN and ozone were calculated based on these data.

\subsection{Exposure tests}

Six continuously stirred tank reactors (CSTR) were set up in the greenhouse of the Experimental Farm of National Taiwan University and used for plant exposure tests with PAN. The cylindrical CSTRs were made of transparent plexiglass plate of diameter $1.2 \mathrm{~m}$ and height $1.8 \mathrm{~m}$, installed with a stirring fan under the roof, a supplementary high intensity lamp $(700 \mathrm{~W})$ above the chamber, and a suction pump with a charcoal scrubber in the rear portion. The layout of the CSTR has been described previously (Sun, 1990). Synthesized pure PAN in tridecane was used to make the gaseous PAN outside the chamber and continuously dispensed into the chambers as described above to obtain a constant concentration of about $15-30 \mathrm{ppbv}$ inside the CSTR.

Seedlings of test plants including spinach (Spinacia oleracea L.), black nightshade (S. nigrum L.), $N$. excelsior, $G$. parviflora Canv., and native cultivars of lettuce ( $L$. sativa $L$.) were grown in a medium containing soil, peat moss, vermiculite, chicken manure, and No. 45 fertilizer (Taiwan Fertilizer $\mathrm{Co}_{\text {.) }}$ that contains $\mathrm{N}, \mathrm{P}_{2} \mathrm{O}_{5}$, and $\mathrm{K}_{2} \mathrm{O}$ in the ratio $15: 15: 15$. They were grown in the greenhouse and exposed to 15-30 ppbv of PAN of 3-6 h in CSTR at temperatures of $23-28^{\circ} \mathrm{C}$, relative humidity of $50-80 \%$, and light intensity of $10,000-50,000$ Lux. After exposure they were moved back to the greenhouse for observation of symptoms during the following weeks. 


\subsection{Field investigation with indicator plants}

Characteristic symptoms of silvering or bronzing on the lower leaf surface of Sword-leaf lettuce or Round-leaf lettuce were periodically investigated in the three major urban areas of Taipei, Taichung and Kaohsiung. Glazing or silvering symptoms on the lower leaf surface of black nightshade were used as a supplementary indicator of PAN. All these indicator symptoms had been proved in previous report (Sun, 1993) to be specific for PAN injury. These two cultivars of lettuce were cultivated by farmers, but the black nightshade was wild. Only plants in good condition of growth were selected for indication of PAN injury in the field.

\section{RESULTS}

\subsection{Ambient concentrations of $P A N$ in Taipei area}

The establishment of the PAN analysis system in 1992 resulted in the first report of ambient PAN measurements in the Taipei area in June 1992 (Sun, 1993). Measurements have continued since that time. The largest daily concentrations recorded from July to December 1992 and from February to April 1993 are shown in Figs 1--3. Generally PAN occurred more frequently in the summer of 1992 than in other seasons, but the largest daily concentration in summer was smaller than that in other seasons.

This investigation showed that PAN typically exceeded 4-12 ppb on heavily polluted days but the greatest PAN concentration of PAN (27 ppb) was measured on 5 February 1993 at about noon. The peak $1 \mathrm{~h}$ mean and peak $3 \mathrm{~h}$ mean concentrations for

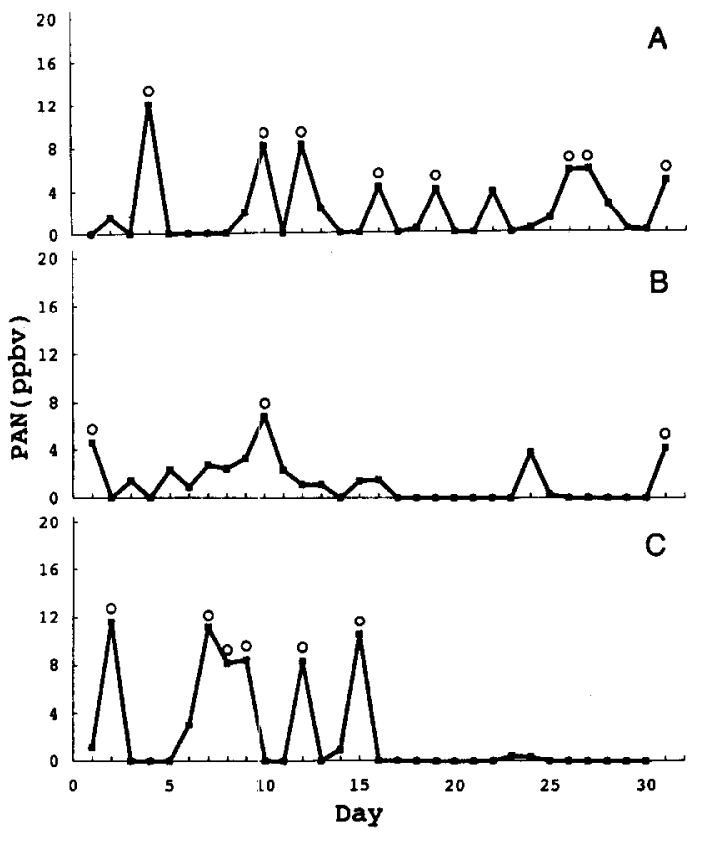

Fig. 1. Daily peak PAN concentrations measured at National Taiwan University at Taipei in July 1992 (A), August (B), and September (C). For each day marked with a circle, lettuce indicator plants showed PAN-type symptoms the following morning.

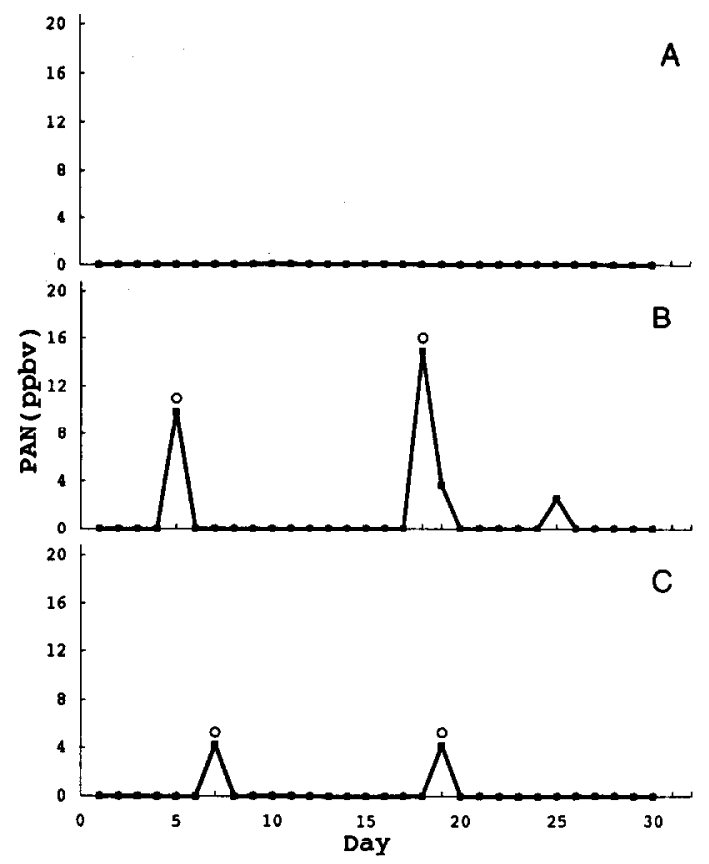

Fig. 2. Daily peak PAN concentrations measured at National Taiwan University at Taipei in October 1992 (A), November (B), and December (C). Lettuce indicator plants showed PAN-type symptoms for each day marked with a circle.

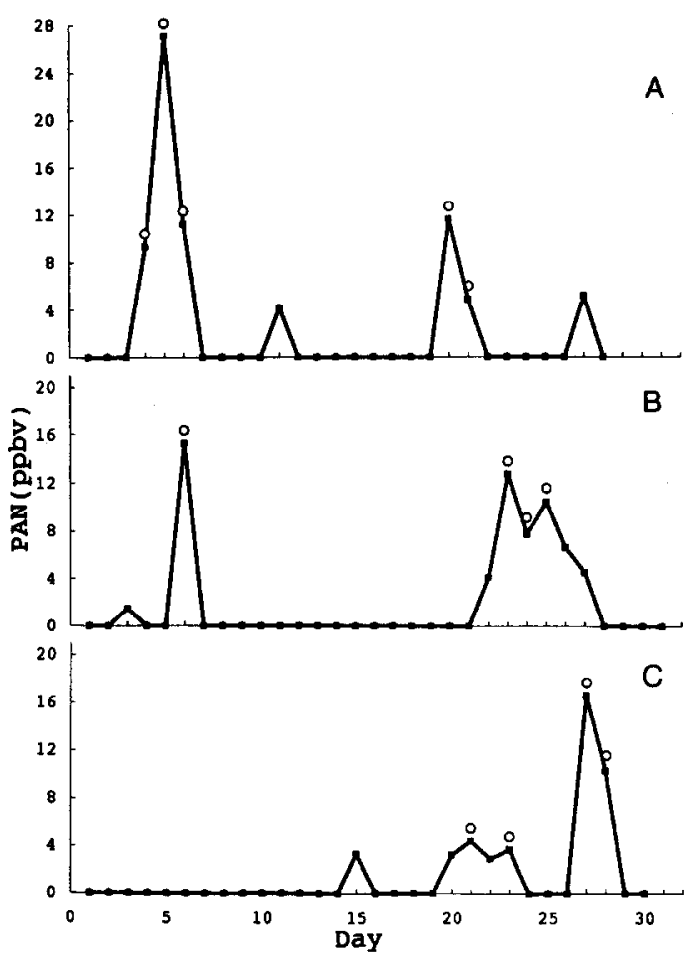

Fig. 3. Daily peak PAN concentrations measured at National Taiwan University at Taipei in February 1993 (A), March (B) and April (C). Lettuce indicator plants showed PAN-type symptoms for each day marked with a circle. 
the same day were 22.5 and $15.0 \mathrm{ppbv}$, respectively. Some sensitive plants such as Sword-leaf lettuce started to show symptoms during the evening of 5 February 1993, whereas others such as black nightshade, G. parviflora, and N. excelsior showed symptoms the next morning. From July 1992 to April 1993 there were at least $34 \mathrm{~d}$ with relatively high concentrations of PAN that affected lettuce and other plants. None of the typical symptoms were observable when the ambient PAN concentrations were lower than 3 ppbv.

\subsection{Relationship between PAN and ozone in Taipei area}

When PAN was detectable in Taipei area, the concentration of ozone generally increased above the $10-20 \mathrm{ppb}$ background value in this area. For the period 25 June 1992-27 March 1993, 31 daily data pairs with significant peak $1 \mathrm{~h}$ mean values of ozone and PAN are shown and compared in Fig. 4. The data from the warm season (25 June-24 November 1992) show that peak $1 \mathrm{~h}$ ozone was highly positively correlated with peak $1 \mathrm{~h}$ PAN with a correlation coefficient of 0.857 and a linear function $Y$ (peak $1 \mathrm{~h}$ ozone) $=16.9 X$ (peak $1 \mathrm{~h} \mathrm{PAN})+13.5$ (Fig. 4A), whereas the data of the cooler season, i.e. 7 December 1992-27 March 1993, show a correlation coefficient of 0.886 and a linear function $Y$ (peak $1 \mathrm{~h}$ ozone) $=3.0 X$ (peak $1 \mathrm{~h}$ PAN) +11.1 (Fig. 4B).

\subsection{Exposure tests}

Plant seedlings of spinach and $N$. excelsior showed silvering and/or glazing symptoms on the lower leaf

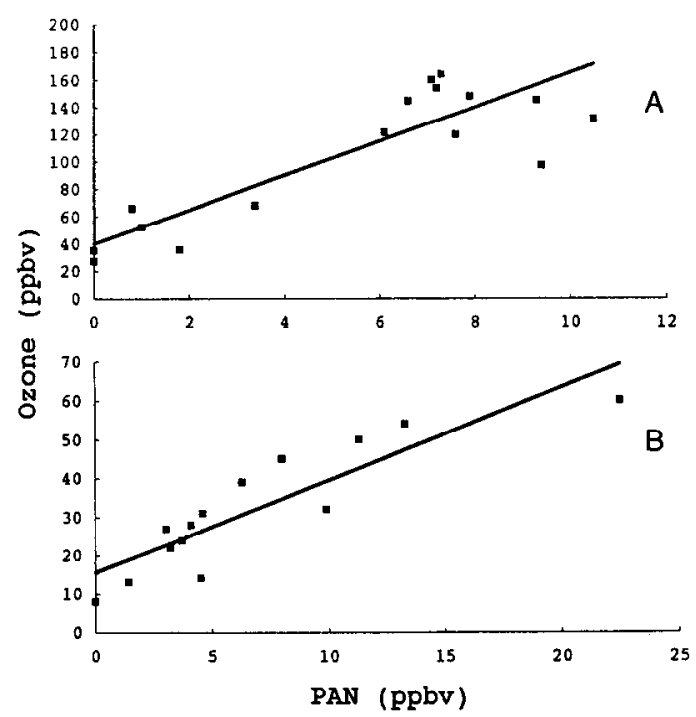

Fig. 4. Relationships between peak $1 \mathrm{~h}$ PAN and peak $1 \mathrm{~h}$ ozone concentrations monitored at Taipei area. (A) The situation of warm seasons from 25 June to 24 November 1992 with 17 selected data pairs. (B) The situation in cooler seasons from 7 December 1992 to 27 March 1993 with 14 selected data pairs. surfaces after being exposed to $28 \mathrm{ppbv}$ PAN in CSTR for $3 \mathrm{~h}$, whereas the major symptoms on black nightshade and $G$. parviflora after the same treatment were glazing and bronzing, respectively. In the same experiment, all cultivars of native lettuce developed the bronzing symptoms that were identical to those described before (Sun, 1993). All these symptoms were similar to those found in the field in Taipei, Taichung or Kaohsiung areas. The threshold dose for plant injury determined in exposure tests in CSTR was $15 \mathrm{ppbv} \times 3 \mathrm{~h}$ for the most sensitive species $G$. parviflora, Sword-leaf lettuces, and black nightshade, $20 \mathrm{ppbv} \times 3 \mathrm{~h}$ for N.excelsior, and $25 \mathrm{ppbv} \times 3 \mathrm{~h}$ for spinach.

\subsection{Field investigation with indicator plants}

Characteristic bronzing or silvering symptoms on Sword-leaf lettuce and Round-leaf lettuce and glazing or silvering symptoms on black nightshade were used as bioindicators of PAN injury in three major urban areas in Taiwan. The investigation was conducted about once a month. Indicator plants showing typical symptoms were recorded as positive and the injury severity was ranked. Results from June 1992 to April 1993 showed that PAN injury occurred in all three cities. The injuries were more frequently found in the seasons from late autumn through winter to early spring in Kaohsiung (the southern) and Taichung (the central) areas, although it occurred all year round in the Taipei basin (the northern) area. None of the symptoms were observable in summertime in Kaohsiung areas where the summer monsoon wind was usually very strong there. Only a few episodes was recorded in Taichung areas in the summertime. The season of most severe pollution in Kaohsiung and Taichung areas was the winter in which there were more calm sunny days.

\section{DISCUSSION}

In the past, PAN was thought to reach phytotoxic levels only in areas of south California, some cities of Japan and The Netherlands (Temple and Taylor, 1983). We found that Taiwan is also an area that has this problem of severe pollution. Generally the injury symptoms were more and more difficult to be observed in the field in southern California and were limited in the early spring scason (P. J. Temple, personal communication). Whereas the PAN-type symptoms are frequently found in all three major urban areas of Taiwan, indicating that the situation is very special or unique at the present time.

PAN measurement data in Taipei showed that concentrations of this pollutant fluctuated greatly. In addition to diurnal change shown in a previous report (Sun, 1993), daily and seasonal variations were also prominent (Figs 1-3). Parallel investigation with indicator plants confirmed the distribution and fluctu- 
ation patterns of PAN levels in the most densely populated area of Taiwan.

PAN was thought to be phytotoxic to plants only at concentrations as high as $15 \mathrm{ppbv}$ (Temple and Taylor, 1983). The results of this work show that 4-5 ppbv of PAN seems to suffice to injure the native cultivars of lettuce and other sensitive species in the field in Taiwan, although results of exposure tests still indicated the requirement of higher levels of this pollutant to cause injury. As the quality of light, i.e. effective spectrum, is an essential factor for plants to show symptoms to PAN (Taylor et al., 1961), altered spectrum of light in the chamber is a plausible reason for the discrepancy of the threshold dose between the chamber and the field.

In addition to previous reports (Sun, 1993) in which pathological relationship between PAN and bronzing or silvering symptoms found on native cultivars of lettuce in the field were given, our work has presented the relation between PAN and characteristic symptoms found on spina.ch, $N$. excelsior, black nightshade and G. parviflora in the field. Exposure of these plants to ozone failed to produce symptoms of these types on these four plant species (data not shown), indicating the validity of using these symptoms as a bioindicator of PAN. These results further confirm the prevailing phytotoxic PAN in the Taiwan areas.

In the Taipei area, ozone is currently monitored by the Taiwan Environmental Protection Administration. The patterns of diurnal alterations were described by Liu et al. (1990). The relationship between ozone and PAN in Taiwan, however, was unknown before. Our monitoring data indicated the co-occurrence of both ozone and PAN at distinct ratios during warmer and cooler seasons (Fig. 4). Generally ozone in Taipei is suppressed in the wintertime, similar to that reported in the temperate countries (Brice et al., 1988). High levels of PAN, in contrast, are detectable in the wintertime both in Taiwan and in the temperate countries, although the concentrations are usually lower in the winter rnonths in temperate zone (Temple and Taylor, 1983; Brice et al., 1984, 1988; Robert, 1990). However, the situation of PAN pollution seems to vary from city to city as phytotoxic levels of this pollutant can be found throughout the yearly cycle in Taipei in the north, but for Taichung in the center and Kaohsiung in the south the injuries were more concentrated in the ccoler seasons rather than in the summertime when the summer monsoon wind is usually very strong there.

The relationship between ozone and PAN was usually expressed by the ozone/PAN ratio (Peake and Sandhu, 1983; Brice et al., 1984). Whereas a linear equation is found to be more appropriate and adopted in this study to describe this relationship as there is always a large value of intercept left in the equation (Fig. 4). However, the phenomenon of higher ozone/PAN ratios in warm seasons and lower ratios in cooler seasons in Taiwan as shown in Fig. 4 is coincident with that reported in the temperate countries (Peake and Sandhu, 1983).

As PAN and ozone co-occurred in the Taipei area, the synergistic effects of these two pollutants on native plant species need to be comprehensively investigated. Temple and Taylor (1985) have shown that there was no synergistic plant effect of PAN and ozone on tomato plants. Recently a study finished in our laboratory also indicated that the co-occurrence of ozone did not synergistically increase the PAN-type symptoms on Sword-leaf lettuce and black nightshade (Tsai, 1994). In addition, the PAN-type symptoms of silvering, bronzing and glazing were usually limited to the lower leaf surface, while the ozone type of bleaching, stippling and flecks were on the upper leaf surface. Therefore the PAN-type symptoms are very reliable for using as a biological indicator and the situation of pollution effects is not so complicated when the ozone was considered in together.

The reason that PAN at a high level exists in all three Taiwan urban areas is still unknown and requires investigation. PAN is produced mostly from the photochemistry of hydrocarbons and nitrogen dioxide. The extraordinarily large numbers of motorcycles with two-stroke engines in Taiwan is a plausible factor for the observation of higher PAN in Taiwan than in other countries where the automobiles predominate. This hypothesis requires further testing.

Acknowledgements-We thank Dr M. P. Buhr of the U.S. National Oceanic and Atmospheric Administration for valuable help in establishing the PAN synthesis and measurement techniques, and the Council of Agriculture, Republic of China, for support.

\section{REFERENCES}

Brice K. A., Penkett S. A., Atkins D. H. F., Sandalls F. J., Bamber D. J., Tuck A. F and Vaughan G. (1984) Atmospheric measurements of peroxyacetyl nitrate (PAN) in rural, south-east England: Seasonal variations winter photochemistry and long-range transport. Atmospheric Environment 18, 2691-2702.

Brice K. A., Bottenheim J. W., Anlauf K. G. and Wiebe H. A. (1988) Long-term measurements of atmospheric peroxyacetyl-nitrate (PAN) at rural sites in Ontario and Nova Scotia; seasonal variations and long-range transport. Tellus 40B, 408-425.

Buhr M. P. (1990) Measurement and chemistry of atmospheric organic nitrates, $212 \mathrm{pp}$. Ph.D. thesis, Dept. Chem. and Biochem., University of Colorado.

Darley E. F., Kettner K. A. and Stephens E. R. (1963) Analysis of peroxyacetyl nitrates by gas chromatography with electron capture detection. Analyt. Chem. 35, $589-591$.

Gaffney J. S., Fajer R. and Senum G. I.(1984) An improved procedure for high purity gaseous peroxyacetyl nitrate production: Use of heavy lipid solvents. Atmospheric Environment 18, 215-218.

Jacobson J. S. and Hill A. C. (1970) Recognition of air pollution injury to vegetation: A pictorial atlas. Air Pollut. Control Assoc., Pittsburg, U.S.A. 
Joos L. F. and Landolt W. F. (1986) Calibration of peroxyacetyl nitrate measurements with an $\mathrm{NO}_{x}$ analyzer Envir. Sci. Technol. 20, 1269-1273.

Katz M. (1977) Methods of Air Sampling and Analysis, 2nd edition, 984 pp. Amer. Publ. Health Assoc., Washington, DC.

Liu C. M., Liu S. C. and Shen S. H. (1990) A study of Taipei ozone problem. Atmospheric Environment 24 , 1461-1472.

Middleton J. T., Kendrick J. B., Jr. and Schwalm H. W. (1950) Injury to herbaceous plants by smog or air pollution. Pl. Dis. Repr. 34, 245-252.

Peake E. and Sandhu H. S. (1983) The formation of ozone and peroxyacetyl nitrate (PAN) in the urban atmospheres of Alberta. Can. J. Chem. 61, 927-935.

Roberts J. M. 1990. The atmospheric chemistry of organic nitrates. Atmospheric Environment 24A, 243-287.

Singh H. B. and Hanst P. L. (1981) Peroxyacetyl nitrate (PAN) in the unpolluted atmosphere: An important reservoir for nitrogen oxides. Geophys. Res. Lett. 8, 941-944.

Stephens E. R. (1969) The formation, reactions and properties of peroxyacetyl nitrate (PAN) in photochemical air pollution. Adv. Environ. Sci. Technol. 1, 119-146.

Stephens E. R., Darley E. F., Taylor O. C. and Scott W. E. (1961) Photochemical reaction products in air pollution. Proc. Amer. Petroleum Inst. Sec. III, 40, 325-338.
Sun E. J. (1990) Sorption of three major air pollutants by bean plants. J. Environ. Prot. Soc. R.O.C. 13, 39-50.

Sun E. J. (1992) Major air pollutants and their effects on vegetation in Taiwan. In Proc. 1992 Joint Int. Symp. on Air Pollution, Soil Microbiology and Biotechnology of Forestry, Taipei, Taiwan, pp. 52-76.

Sun E. J. (1993) Effects of peroxyacetyl nitrate on lettuce plants in Taiwan. Plant Pathol. Bull. 2, 33-42.

Sun E. J. and Su H. J. (1985) Fluoride injury to rice plants caused by air pollution emitted from ceramic and brick factories. Envir. Poll. (Ser. A) 37, 335-342.

Taylor O. C., Dugger W. M., Jr., Cardiff E. A. and Darley E. F. (1961) Interaction of light and atmospheric photochemical products ('smog') within plants. Nature 192 , 814-816.

Temple P. J. and Taylor O. C. (1983) World-wide ambient measurement of peroxyacetyl nitrate (PAN) and implications for plant injury. Atmospheric Environment 17, 1583-1587.

Temple P. J. and Taylor O. C. (1985) Combined effects of peroxyacetyl nitrate and ozone on growth of four tomato cultivars. J. Envir. Qual. 14, 420-424.

Tsai M. C. 1994. Effects of ozone on vegetation in Taiwan area, 94 pp. M.S. thesis, Department of Plant Pathology and Entomology, National Taiwan University, Taipei, Taiwan, R.O.C. 